\title{
The Experiences of Mental Health Professionals Supporting Forced Migrants: A Qualitative Systematic Review
}

\author{
IONA MYFANWY TYNEWYDD, SOPHIE NORTH, AND IMOGEN RUSHWORTH
}

\begin{abstract}
Many forced migrants experience trauma in pre-migration, journeying, and post-migration phases of flight. Therefore appropriate mental health provision is required. Whilst previous reviews have explored the experiences of health-care staff in supporting forced migrants, no review was found that focused solely on the experiences of mental health professionals. This qualitative thematic synthesis integrates the findings from ten qualitative studies and identifies analytical constructs that encompass the challenges and facilitators for mental health professionals. Findings will inform how services can be developed to best support staff and enable the provision of high-quality mental health care for this potentially vulnerable population.
\end{abstract}

\section{Résumé}

Plusieurs migrants forcés vivent un trauma lors de la prémigration, du voyage et de la post-migration. Une offre adéquate en santé mentale est donc nécessaire. Alors que des études précédentes ont exploré les expériences du personnel des services de santé dans le soutien aux migrants forcés, aucune études axée seulement sur les expériences des professionnels en santé mentale na été trouvée. Cette synthèse thématique qualitative intègre les résultats de dix études qualitatives et identifie les constructions analytiques englobant les obstacles et les facilitateurs pour les professionnels en santé mentale. Les résultats sont susceptibles d'orienter le développement de services visant à mieux soutenir le personnel et permettre la prestation de soins en santé mentale de qualité pour cette population potentiellement vulnérable.

$\mathrm{H}$ ealth consequences for forced migrants are vast, multifaceted, and greater than for "regular" migrants. ${ }^{1}$ Traumatic events in pre-migration and "in-flight" phases, and post-migratory stress are linked to higher levels of distress. ${ }^{2}$ These stressors influence forced migrants' abilities to engage in treatment and resettlement in post-migration phases. Distress may be further amplified by physical and social care needs, such as illness or housing issues. ${ }^{3}$ Uncertain immigration status may also intensify fears of deportation and reduce feelings of safety. ${ }^{4}$ Forced
(C) Iona Myfanwy Tynewydd et al., 2020. This open-access work is licensed under a Creative Commons Attribution-NonCommercial 4.o International Licence, which permits use, reproduction, and distribution in any medium for non-commercial purposes, provided the original authorship is credited and the original publication in Refuge: Canada's Journal on Refugees is cited.
Cette œuvre en libre accès fait l'objet d'une licence Creative Commons Attribution-NonCommercial 4.o International License, laquelle autorise l'utilisation, la reproduction et la distribution de l’euvre sur tout support à des fins non commerciales, pourvu que l'auteur ou les auteurs originaux soient mentionnés et que la publication originale dans Refuge: revue canadienne sur les réfugiés soit citée. 
migrants thus comprise a vulnerable population necessitating significant support for diverse and complex mental health needs.

There are a number of difficulties in identifying those requiring mental health support. 5 Professionals in mental health services may not have received training that enables them to identify and support the types of mental health difficulties experienced by forced migrants. ${ }^{6}$ Language may also act as a barrier. ${ }^{7}$ Furthermore, psychological approaches may be unfamiliar and uncomfortable within different cultural backgrounds or may evoke stigmatizing connotations. ${ }^{8}$ Further challenges may be presented by specific stressors associated with forced migration, such as human rights violations and interpersonal violence. ${ }^{9}$ These experiences may cause difficulties in trusting others, thus presenting challenges to care. There are a number of challenges, therefore, to providing appropriate and effective mental health support for forced migrants in the post-migratory phase.

\section{Qualitative Reviews}

The need to investigate properties of effective health services for forced migrants is widely acknowledged. ${ }^{10}$ The number of studies is rapidly expanding, with a number of qualitative studies being undertaken across several countries and different health-care services. Qualitative research is of particular significance to evidence-based health care, because it seeks to explore the human experiences of health-care interactions and processes. ${ }^{11}$ The synthesis of qualitative research, however, provides superior insight because its product allows supplementary understandings of the phenomena and their operations. $^{12}$

Two recent qualitative systematic reviews of particular relevance have been identified. Robertshaw et al. reviewed challenges and facilitators for primary health-care professionals working with refugees and asylum seekers post-migration. ${ }^{13}$ This review assessed experiences of doctors, nurses, and midwives providing health care in high-income countries. Twenty-six articles were analyzed thematically, producing three analytical constructs of health-care encounter, healthcare system, and asylum and resettlement. Within these constructs, eleven themes relating to a range of challenges and facilitators were situated. In relation to the health-care encounter, a trusting relationship, communication, cultural understanding, health and social conditions, and time were identified as themes. Training and guidance, professional support, connecting with other services, organization, resources, and capacity were themes identified as relevant to the health-care system. Quality assessment revealed the included articles varied in quality. The review employed a transparent methodology, improving the validity of findings and conclusions. It highlighted a need to investigate mental health professionals' experiences to further contribute to improved service provision for forced migrants.

The second review explored refugee and staff experiences of psychotherapeutic mental health services in countries of resettlement. ${ }^{14}$ It aimed to address the lack of service-user perspective present in refugee service literature. The review was limited to articles containing the word refugee in the title, alongside terms relating to psychotherapeutic input and qualitative studies in the abstract. Therefore the review may not have identified studies that concerned asylum seekers or other forced migrants or had idiosyncratic titles. This limits the extent to which the findings can be generalized to clinical care, since the findings apply only to those granted refugee status and are not wholly representative of forcibly displaced persons presenting for care. The review included eleven studies: five involving service users and six involving staff. Whilst considering both the perspectives of service users and staff is important and valid, unique elements unsuited to being grouped in this way may have been compromised. Similarly, the included studies involved both individual and family client groups. Quality assessment revealed the majority of included studies had poor or very poor quality. Combined elements of thematic synthesis and meta-ethnographic approaches were utilized in the analysis. Mutual understanding, addressing complex needs, discussing trauma, and cultural competence were identified as key themes in achieving acceptable care.

The aim of the current review is to explore the experiences of mental health professionals providing support to forced migrants. Previous systematic reviews have identified a range of challenges and facilitators for health professionals providing care for forced migrants. ${ }^{15}$ This review aims to explore the challenges and facilitators of mental health professionals-a novel area of focus. This review will also address limitations of the prior reviews in health-care provision. To enhance credibility, it will consider a single perspective, so that the results relate to this specific population. This will also allow improved generalizability to other mental health professional settings. The review will not be limited to professionals working with those with refugee status, but to professionals working with any forced migrant population, including those who have not yet been granted refugee status. Thus, it will encapsulate the experience of working with persons who are awaiting confirmation of their immigration status and who do not have the rights associated with refugee status (and the distress associated with these factors). It will encompass public, private, and/or charitable sector mental health services. Thus, this is the first comprehensive review of mental health service professionals' experiences. Improved understanding of these elements and their implications is vital for policy-making, staff support, 
refugee* OR asylum seek* OR forced migrant*

AND qualitative OR qualitative research OR mixed method OR experienc* OR perception* OR attitude* OR perspective* OR challenge* OR facilitator* OR barrier*

AND mental health OR mental health service* OR mental health prov* OR healthcare OR health care OR service prov* OR care prov* OR profess* OR staff* OR counsel* OR psycholog* OR psychi* OR therapi* OR psychothe* OR mental health practitio* OR MHP OR mental health nurs* OR social work* OR occupational ther* OR support work*

Figure 1. Search strategy

and well-being, and provision of quality services for forced migrants. ${ }^{16}$

\section{Review Question}

What are the challenges and facilitators experienced by mental health professionals providing support to forced migrants?

\section{Method}

\section{Search Strategy}

The search strategy was pre-planned and registered with PROSPERO International prospective register of systematic reviews (ID: CRD42017084617). The strategy sought all available relevant articles. MEDLINE Complete (EBSCO), Web of Science (Web of Knowledge), Psycinfo (ProQuest), and CINAHL Complete (eBsco) were searched on June 4, 2018. These sources were selected for their scope and coverage of literature pertaining to health, psychology, and clinical practice.

Search terms for forced migrants, mental health professionals, and qualitative research were combined to search article titles and abstracts. Both free text and MeSH terms were used. The search strategy was informed by the Sample, Phenomenon of interest, Design, Evaluation, Research type (SPIDER) tool. Compared to the established PICO (Population/problem, Intervention/exposure, Comparison, and Outcome) tool, SPIDER terminology is more suited to qualitative research and produces more manageable results. ${ }^{17}$

Google Scholar was utilized to identify further articles meeting the review criteria through hand-searching and footnote chasing to improve search comprehensibility. ${ }^{18}$ Use of supplementary techniques is critical as the result of issues associated with locating relevant qualitative literature. ${ }^{19}$ These include the low concentration of qualitative studies within databases, indexing variation between databases, and the use of quotations as article titles.

All search results were imported into Zotero. Duplicates were removed and the remaining titles and abstracts were screened by the first author. Articles clearly not meeting the inclusion criteria were excluded. Remaining articles were assessed according to the pre-specified study selection criteria by assessment of the full-text articles.

\section{Inclusion Criteria}

Qualitative and mixed method studies with a qualitative component exploring experiences of mental health professionals working with forced migrants were included in this review. Forced migrants were defined as asylum seekers, refugees, or other forcibly displaced migrants. All types of mental health professionals were included. Articles had to include at least some analysis in narrative form (e.g., firstperson quotes) on mental health professionals' experiences and perspectives. Eligible data collection methods included verbal interviews, focus groups, or free-form questionnaire and survey data. Only studies where mental health professionals worked directly with forced migrants were included. Articles where recipient data were presented alongside other data were included. Published, peer-reviewed articles were included. No limits on year or geography were applied in response to the limited availability of source material. NonEnglish-language studies were considered if an English translation was available.

\section{Exclusion Criteria}

The following studies were excluded: quantitative studies; theses; dissertations; opinion articles; organization reports; reviews and case studies; studies exploring experiences of professionals providing physical health care; interpreters or informal carers; studies exploring only the experiences of service users (forced migrants); studies in which participants did not have direct, exclusive experience of working with forced migrants; studies concerning refugee camps, asylum seeker detention centres, or specialist services. Where no English language text was available, studies were excluded. 


\section{Data Extraction}

Study characteristics including aims, setting, participants, methodology, results, and implications were extracted by the first author. As noted by Barroso et al., identification of findings was complicated by reporting variation and integrity. ${ }^{20}$ Findings were taken to refer to more than direct quotation and data summation. Therefore all text under the headings "results," "discussion," and "conclusions" were extracted electronically and entered into QDA Miner Lite.

\section{Assessment of Quality}

Quality appraisal was conducted independently by the first author and reviewed by all authors. The Critical Appraisal Skills Programme (CASP) tool for appraisal of qualitative research was employed. The tool was developed in relation to medical literature and piloted with health-care practitioners and highlights procedural issues and reporting standards in qualitative research. ${ }^{21}$ The comparative strengths of the studies were critically appraised and evaluated. No scoring system was used, as according to the purpose of the tool. Exclusions were not made based on quality appraisal, as the result of the following. First, there remains ongoing debate regarding the use of tools in this manner in qualitative research. Second, there is some suggestion of structured quality assessments bias in favour of research practice compliance over the value of contribution to the field; thus, inclusion enhanced the wealth and richness of the synthesis. ${ }^{22}$ This is especially pertinent, given the lack of literature seeking to understand the experiences of mental health professionals working with forced migrants.

\section{Data Synthesis}

The recognized methodology for systematic review and thematic synthesis of qualitative research detailed by Thomas and Harden was utilized. ${ }^{23}$ This methodology has particular value in informing health-related policy and practice. ${ }^{24}$ Moreover, it provides a transparent account of the synthesis stages and derivation of conclusions. ${ }^{25}$ The Enhancing Transparency of Reporting the Synthesis of Qualitative Research (ENTREQ) framework was utilized to guide the review reporting. ${ }^{26}$

Initial line-by-line coding was completed by hand by the first author in QDA Miner Lite. All primary quotations and interpretations related to the experiences of mental health professionals working with forced migrants were coded openly. An inductive process of theme derivation ensured the most complete representation of perspectives and experience. Inductive derivation reduces the risk of unanticipated emergent themes being obscured or overlooked by limiting the scope of the analysis to specific questions or theories. Subsequent studies were translated into the catalogue of pre-existing concepts where appropriate, and new concepts were created when deemed necessary. Initial codes were organized into descriptive themes of related constructs that closely related to original findings. In the final stage of synthesis, analytical themes were generated in order to produce understandings and notions that exceeded those of the primary studies. ${ }^{27}$

\section{Results}

\section{Study Selection Results}

Systematic database searching identified 7,922 studies. A further 12 studies were identified through hand searching and reference list searches. Thus, the total number of studies identified was 7,934. A total of 2,722 duplicates were removed, and a further 5,165 studies were excluded after screening titles and abstracts. Full-text articles of the remaining 47 studies were sought for eligibility assessment. Full-text articles could not be obtained for four studies; therefore, they were excluded. Ten articles met the full eligibility criteria and were included.

\section{Study Characteristics}

All included studies were qualitative. Four were from the United Kingdom, five from Australia, and one from the United States. All articles were published between 2007 and 2018. The number of participants ranged from seven to seventeen, yielding a combined total of seventy-nine participants. Participant samples in all except three studies were exclusively mental health clinicians. The combined sample included clinical psychologists, counselling psychologists, psychologists/general psychologists, counsellors, social workers, psychotherapists, psychiatrists, marriage and family therapists, "front-line clinicians," administrative and managerial staff, a trainee clinical psychologist/trainee psychoanalyst, a psychotherapist/social worker, an occupational therapist, and a community development worker. All studies employed semi-structured interviews. To analyze data, four utilized a thematic approach, three used discourse analysis, two used an interpretative phenomenological approach, and one a constant comparison framework.

\section{Quality Assessment}

The CASP critical appraisal tool was used to evaluate procedural issues and transparency of the included studies. The appraisal revealed variability in the quality of the ten articles, with none of the articles satisfying all quality criteria. All articles gave a statement of the research aims; however, there was variability in how explicitly they were stated and in detailing the importance and relevance of the research. The chosen 


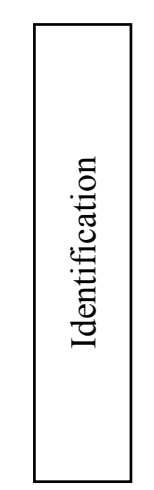

Records identified through database searching (MEDLINE $n=$ 1589; Web of Science $n=3861$;

PsycINFO $n=1483$; CINAHL $n=$ 989)

$(n=7922)$
Additional records identified through other sources (Hand searching using Google Scholar $n=10$; Reference list searches $n=2$ ) $(n=12)$
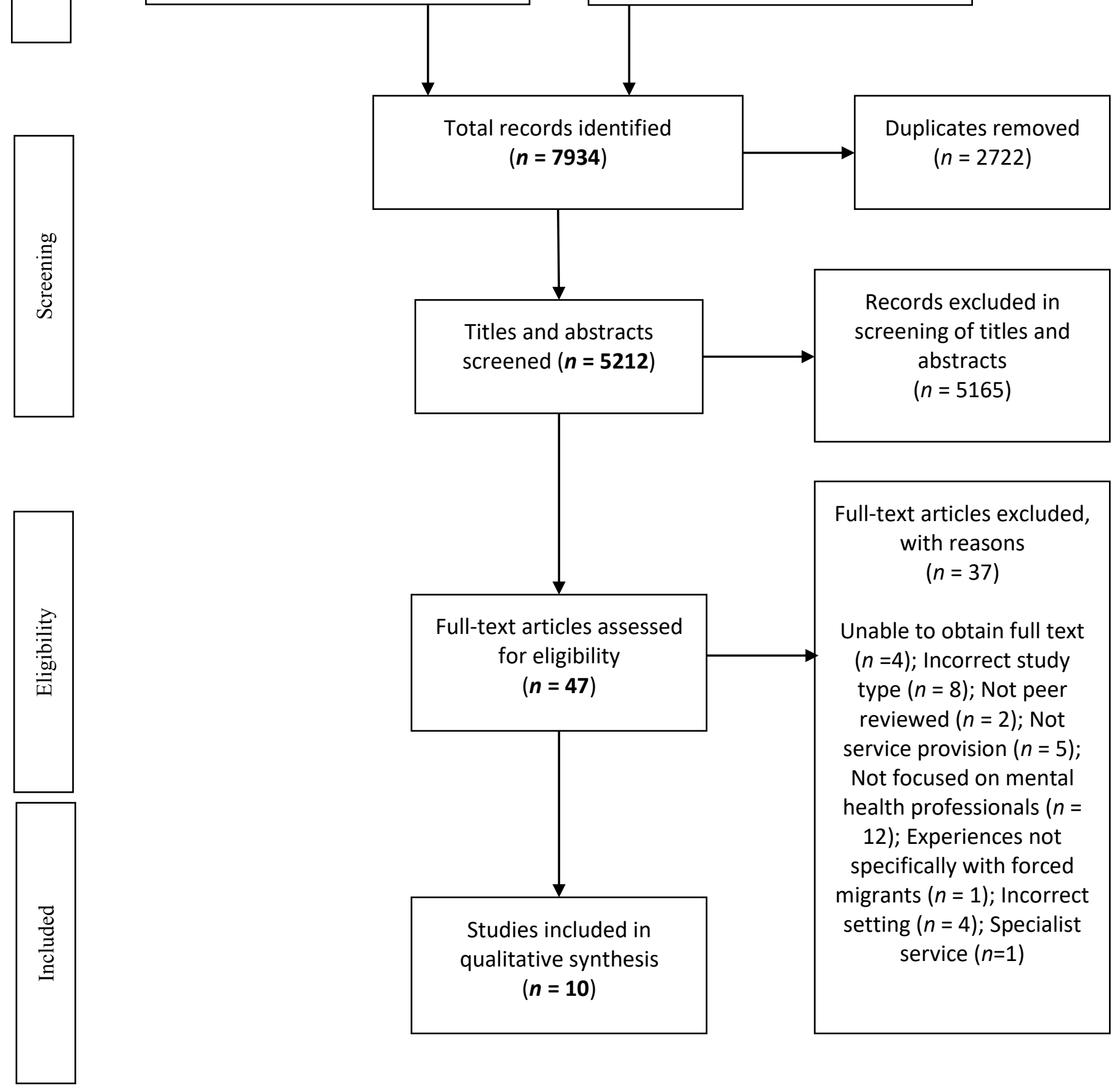

Figure 2. Article selection 
Table 1. Analytic constructs

\section{Analytical construct}

Professionals must be aware of and contend with power differentials

Professionals must develop specialist knowledge and skills

Witnessing forced migrants' stories and trauma significantly affects professionals
Challenges

Working within complex and hostile frameworks

Discomfort at one's relative privilege

Working sensitivity with cultural differences

Holding and balancing forced migrants' competing care needs

Challenging negative social narratives about forced migration

Supervisors lacking expertise in forced migration

Coping with vicarious responses to stories of horror

\section{Facilitators}

Being in a position to "make a difference"

Focusing on the importance of the work

Networking with other professionals working with forced migrants

Developing professionally in this specialization
Witnessing the strength of forced migrants in their stories

Support and care from professionals' organizations

Prioritizing self-care.

Growing and developing personally in response to the work research method was appropriate across studies. A minority of studies explicitly stated the research design. Most detailed the sampling strategy, and the majority made some reference to eligibility criteria. There was wide variety in the reporting of participant demographic information, and possible reasons for non-participation were not discussed by any articles.

All articles stated the data collection method, and most provided some justification. Whilst two detailed their full interview schedule, the remainder gave only general descriptions of the interview schedule content. Less than half of the studies gave the location of data collection, and one identified the interviewer. Theoretical saturation was also largely not discussed. Six of the articles made either explicit reference to reflexivity or addressed issues relevant to it. The manner in which this was addressed was mixed, with some authors describing their motivations for undertaking the research and exploring potential consequences, and others stating methods employed in an effort to reduce bias.

There was wide variety in the reporting of ethical issues. Three articles made no reference. The remaining articles stated the study had ethical approval, and all except one gave details. Three articles evidenced participants being fully informed about the study. Five reported consent and/ or withdrawal was discussed with participants, and one gave details regarding maintenance of confidentiality.

Nine articles gave full descriptions of the analysis employed, and all except two justified use of the approach utilized. All clearly presented their findings and gave support in the form of quotations, although the rationale for including presented data was discussed in only two. Contradictory data and the role of researchers were rarely discussed. All articles discussed study findings and their value in relation to wider literature, practice, and/or policy. Most addressed credibility, with five explicitly discussing the study strengths and limitations. Seven explored directions for future research.

\section{Synthesis Output}

To ensure the review question did not limit the themes produced by the analysis, an inductive bottom-up thematic analysis was initially conducted, as detailed by Thomas and Harden. ${ }^{28}$ Line-by-line coding and translation of concepts gave rise to an initial catalogue of forty-four codes. Through evaluating similarities and differences between the initial codes, a hierarchical framework of descriptive themes was produced. Three higher-order themes encompassing twelve descriptive themes were embedded within this structure. 

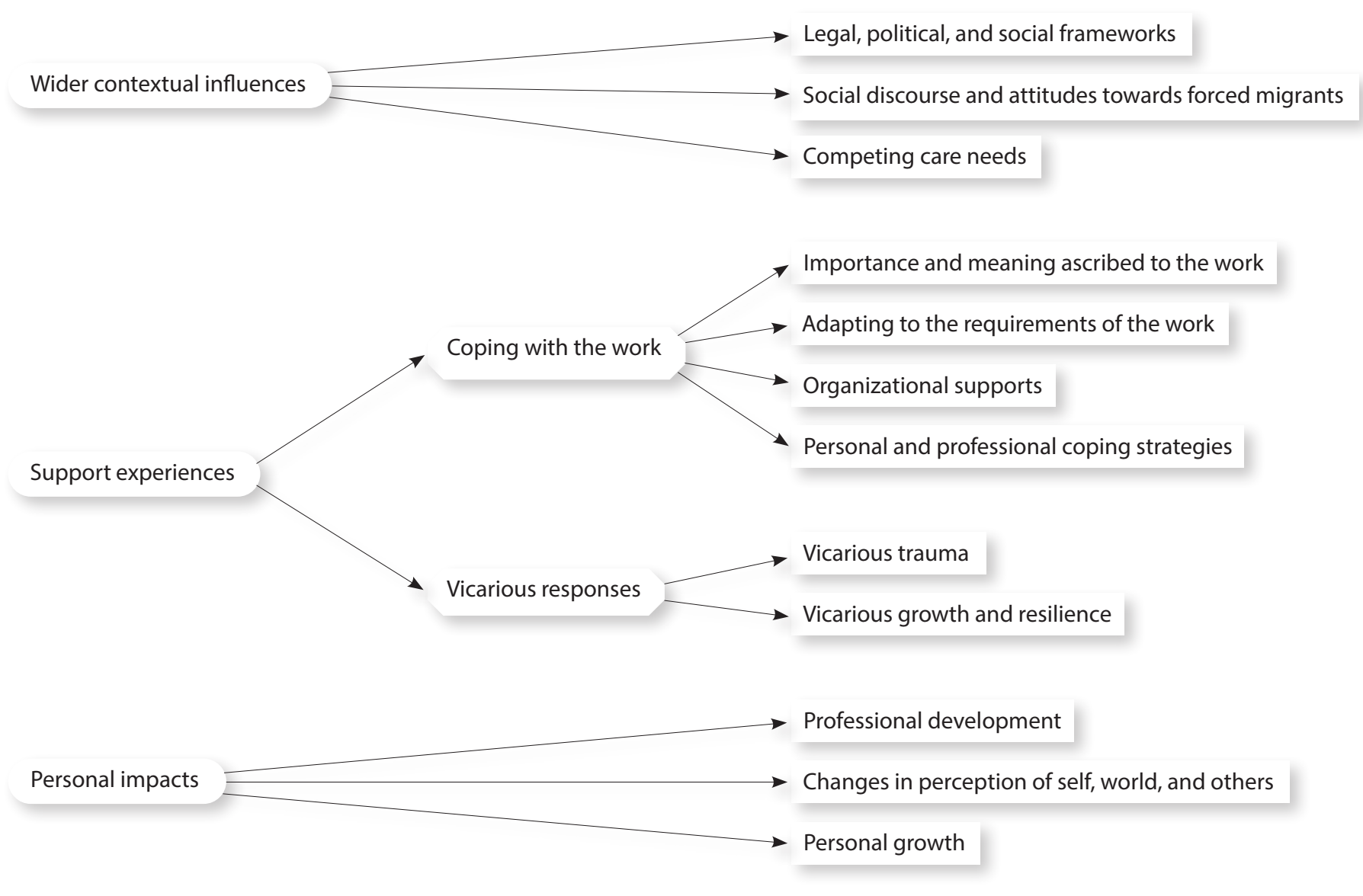

Figure 3. Hierarchy of descriptive themes

To address the review questions, and to generate understandings that exceeded those of the primary studies, analytical themes were derived through the iterative process described by Thomas and Harden. ${ }^{29}$ This step of "going beyond" descriptive themes can be considered the defining feature of synthesis. Challenges and facilitators were inferred from the descriptive themes using the information and context within the journal articles. Related implications for clinical practice were also considered. From this process, analytical themes began to develop. The challenges and facilitators were then re-examined and refined within the context of these analytical themes. This iterative process continued until the analytical themes encapsulated the original descriptive themes, inferred challenges and facilitators and clinical implications. Through this process, three analytical themes emerged, encompassing relative challenges and facilitators of professionals' experiences.

\section{Analytical Construct 1: Professionals Must Be Aware of and Contend with Power Differentials}

All of the studies described issues of power present at multiple levels, both within and beyond the health-care interaction.

Challenges: Working within Complex and Hostile Frameworks, Discomfort with One's Relative Privilege

All studies except one highlighted the strain placed by outside systems and frameworks on professionals in supporting forced migrants' mental health. Professionals cited the time and energy this detracted from their ability to focus on their remit, the direct influence of wider systems on the emotional states of service users, and the impact of being perceived to be part of "the system" on the therapeutic relationship.

"You come up against a system which is meant to be there as backup for support in your role, but it's not functioning adequately. It can make you feel like the pressure is actually on you."30 
"When they come here, they, by being detained and by being actually treated in this way basically ... it reinforces the message that was previously given by the government from the country they belong to, that actually you are not a person with full rights, you know, having dignity and so on, so this unfortunately, the psychological effect on them, basically they are not believed, they are not validated."31

A number of professionals reflected on an awareness of their own privilege and powerful status having been highlighted to them. This was constructed as an uncomfortable realization, and professionals spoke of struggles in "coming to terms with" and accepting injustices in others' lives.

"Being a nice, white, middle-class male who is kind of sheltered from the awful things that happen on the whole around the world and lucky, and you can walk around in your own little bubble, or when you are working with asylum seekers and refugees you ... you are forced to confront what's really going on. And by "what's really going on" I mean wars and torture in other countries, but then also the social reality of life in the uk for people." ${ }^{2}$

\section{Facilitator: Being in a Position to "Make a Difference"}

Holding a position of relative power was also viewed as a positive enabler in effecting change in almost every included study. Feeling able to elicit some influence over forced migrants' well-being, or assuming an active political stance gave professionals a sense of purpose and of "doing good." This was cited as a significant motivator.

"When I do trainings, when I speak in public, when I testify in court, I'm helping to publicize and speak out against and document the impact of these injustices. So to me that connects with my sense of resilience." 33

\section{Analytic Construct 2: Professionals Must Develop Specialist Knowledge and Skills}

All the studies explored how the uniqueness of the forced migrant experience itself affected a variety of related issues. These issues again had influence within and beyond the immediate health-care interaction.

\section{Challenges: Working Sensitively with Cultural Differences, Holding and Balancing Forced Migrants' Competing Care Needs, Challenging Negative Societal Narratives about Forced Migration, Supervisors Lacking Expertise in Forced Migration}

Cultural differences contributed to challenges for professionals' experiences in the majority of included studies.
First, professionals spoke of this limiting forced migrants' knowledge and access to services, and giving rise to distress through acculturation and assimilation. Linguistic barriers and use of interpreters were commonly cited as having a negative impact on support overall.

"[It's] frustrating at times because of the lack of language, the ongoing struggle to understand other perspectives and other cultures." 34

Second, as a result of the multiple and often competing care needs of forced migrants, professionals found mental health was seldom prioritized. Some professionals contended with this by becoming flexible in their role and supporting forced migrants in meeting other care needs, whilst others maintained firm boundaries in their role and remit.

"In terms of dealing with other stuff they come to see us about, they're not in a head space to even get into that deeper stuff. They're still trying to deal with the practical things they have to do to get through each day, and all of the different stresses around immigration, accommodation, finances." 35

"I am social worker, I am a lawyer, I am everything that you can think of.... However, having said that, I don't do that with every patient. I refer sometimes to other agencies to do that, but I do that when I think doing it is right." 36

Third, a further challenge in the uniqueness of the forced migrant experience was that of negative social attitudes and discourse, detailed by five studies. This is seen as attributing to difficulties with identity formation and assimilation for forced migrants, both of which influence emotional well-being.

"I've had friends and family talk about refugee people, people on the news, and all those sorts of people, and it's like, well hang on, and I'm able to articulate it in a way so it helps them understand the difference, you know, in what's happening." ${ }^{37}$

Fourth, two studies found professionals felt under-supported by their supervisors because they lacked supervisory experience. Participants raised concerns about a lack of supervisory provision and expertise, and increased risk as a result.

"I think the problem is that supervisors often have less experience than you do in working with refugees and asylum seekers. And that is really troubling you know, and so you get them kind ... they are in a position of trying to guide you but they can't really direct you." 38 
Facilitators: Focusing on the Importance of the Work, Networking with Other Professionals Working with Forced Migrants, Developing Professionally in This Speciality

Seven of the ten studies explored how acknowledging the meaning and value of the work aided the mental health-care process. Focusing on positive changes that had occurred, however small, was also endorsed by several professionals. 39

"Even though it is going to take time, even though it is going to take years, even though the healing is not going to be complete, you can see in clients when you work a long time here, you can see how life changes in ways that you never thought could happen. If you can see it is like this, you have this motivation to continue to work and to continue encouraging them to do things, [to keep] helping them." 40

Participants advocated peer support in four of the studies as facilitating their ability to provide care for forced migrants. Benefits included emotional support and being able to relate through shared experiences.

"I've ended up linking up with colleagues and ... and in a way doing much more peer supervision.... Colleagues who I know are particularly interested in the cross-cultural." ${ }^{41}$

The development of competency and expertise was also viewed as a facilitator and positive benefit. Five studies noted how professionals were able to develop specialist skills through working with people who were asylum seekers and refugees, and who had experienced trauma.

Five clinicians ( 41.7 per cent) experienced a sense of increased personal or professional development as a result of their work and described it as a reward of assisting people from refugee backgrounds. Some reported having a deeper understanding of trauma work and how to support clients, and some reported feeling more confident in their therapeutic skills and abilities. For instance, "I think I feel much, much more comfortable when working with people from different backgrounds." 42

\section{Analytic Construct 3: Witnessing Forced Migrants' Stories and Trauma Significantly Affects Professionals}

The final construct encompasses the direct and indirect effects that supporting people who had experienced, and continued to experience, trauma relating to their displacement had for professionals.

\section{Challenge: Coping with Vicarious Responses to Stories of Horror}

Professionals in all studies described the challenges of coping with the trauma they were exposed to through their work. They detailed how difficult it was to hear about forced migrants' experiences, and how this resonated with them outside of their work. Emotional implications included feelings of being overwhelmed, powerless, unsafe, underprepared, or detached. In seven studies professionals experienced nightmares, flashbacks, and other responses to trauma that mirrored those of the people they were supporting.

"I just feel that there is nothing safe and that's the rest [sic] of working in trauma because if, your whole world is unsafe outside because ... because you just see the awful stories, you see, we see torture survivors, we see what the worst that a human being can do to another human being." 43

"I used to go to the supermarket and feel like I had bubble wrap, like Glad wrap, just around me, like this kind of coating. I would go there and I just felt like I was going from this horror world into normal land, and then I didn't feel connected to people in normal land. Like I was going, "You don't get it; you didn't hear what I heard!"44

\section{Facilitators: Witnessing the Strength of Forced} Migrants in Their Stories, Support and Care from Professionals' Organizations, Prioritizing Self-Care, Growing, and Developing Personally as a Result of the Work

Witnessing strength and growth were consistently regarded as positive, motivating aspects of supporting forced migrants. Professionals experienced this as rewarding through empowering, helping others to find meaning and improve their relationships and connections. Some described feeling awe and respect for those they supported, and feeling privileged and honoured to work alongside them.

"It's the inner strength of the person. You know, you can feel that flame and you think I shall want to it keep alight, I don't want it to be crushed anymore, and they only seem to need a little bit of support for them to go ahead on their own." 45

"It feels like an absolute privilege to sit with [these] people and hear their stories, to be the person that they are willing to trust when they don't trust anybody else. You know, to be the person that they trust with that level of information, that depth of trauma and horror." 46

Participants in six of the studies expressed the importance of organizational support in coping with their work, 
although some called for greater support. Overall, provision of supervision, training, and opportunities for professional development was considered facilitative.

“There's a lot of support here. They make it really clear that if you ever feel you need to talk to someone, it doesn't matter when it is, there is always someone you can just ask to speak to, whether it's a supervisor or it's another colleague, just grab someone and go and talk." 47

In addition to organizational support, self-care strategies were advocated in four studies. Participants utilized individual self-care strategies, informal support from friends and family, and sought support through formal care (e.g., counselling). To look after themselves, participants reported engaging in practical strategies, including relaxation, sports, taking appropriate breaks, and ensuring that they maintained achievable personal schedules.

In nine of the ten studies, professionals experienced personal growth through their work, which helped them to continue. This occurred in increased acceptance of others, spiritual growth, and altered perceptions of themselves, their values, and the world.

"It just helped bring it more to home on a personal level to want to do so much more, to bring equality to this earth." 48

"[The work] makes you strong. [I'm] a stronger person than I used to be." 49

\section{Discussion}

Three analytical constructs encompassing challenges and facilitators for professionals providing mental health care to forced migrants emerged from the thematic synthesis. The first construct, "Professionals must be aware of and contend with power differentials," acts as a barrier when supporting someone within complex legal, financial, and housing systems. This is consistent with the review of professionals' experiences of treating physical health, ${ }^{50}$ which also noted surrounding systems are not only complex, but often unfavourable to forced migrants. Becoming aware of one's privileges and the lack of privileges of those being supported also poses a challenge for professionals. Power differences between mental health professionals and service users have readily been identified as impeding recovery. In working with this particular population, imbalances of power are likely to be more pronounced and have a greater impact. Literature extensively documents how disempowerment and marginalization affect forced migrants. These include poverty, racism, and discrimination, amongst others. ${ }^{51}$ Asylum processes and associated policies themselves often further disempowerment. ${ }^{2}$ These circumstances, along with uncertainty, frequently increase psychological distress and increase the task before mental health professionals. ${ }^{53}$ Therefore professionals may need to conscientiously acknowledge and reduce power imbalances (where possible) to work effectively with and empower forced migrants. Having a safe space to reflect on and process these thoughts and feelings also helps to ensure the well-being of professionals.

Conversely, the findings show being in a position to "make a difference" promotes professionals' abilities to successfully support, advocate for, and empower forced migrants. Whilst little evidence has been found examining the impact of clinician self-efficacy on mental health outcomes, preliminary evidence indicates counsellor self-efficacy correlates with treatment outcomes. ${ }^{54}$ Our review indicates that a sense of trust, choice, and power is highly important to mental health service-users' feeling safe and engaging with therapeutic processes. ${ }^{55}$ Moreover, interventions that emphasize empowerment are consistently found to be more effective in child and adult mental health settings. ${ }^{56}$

The second construct, "Professionals must develop specialist knowledge and skills," highlights themes uniquely concurrent in the forced migrant experience. Clinicians must be aware of cultural differences, competing care needs, negative societal attitudes towards forced migrants, and scarce expert supervision. The first two of these themes were present in both health-care professionals' experiences of working with forced migrants in relation to physical health, ${ }^{57}$ and service-provider and user experiences in psychotherapeutic services for refugees. ${ }^{58}$ It would appear these challenges may be consistent across health-care settings. There may be an opportunity, therefore, for professionals from different backgrounds, including health care, mental health, and/or psychotherapeutic services to discuss and develop ways of working competently and sensitively with the cultural differences and competing care needs often synonymous with forced migration. Additionally, increasing "cultural competence" is strongly advocated for by an increasing body of literature to improve services for forced migrants. 59

The impact of negative societal attitudes is widely documented as adversely affecting refugee and asylum seekers' mental health. ${ }^{60}$ It follows that those compassionately supporting these individuals may also experience these effects. There is limited discussion of this in the literature, however. Paluck and Green's review found mixed evidence on reducing prejudice generally. ${ }^{61}$ It is pertinent, therefore, that research seeks to understand how these effects might be mitigated for professionals. The specific issues raised in relation to supervision-in particular a lack of expertiseseem to be relatively novel findings. Effective clinical supervision demonstrably improves job satisfaction, stress levels, 
burnout rates, and clinical outcomes. ${ }^{62}$ The findings indicate access to quality supervision is of great importance, more so given the specialist and complex care needs of the forced migrant population.

Facilitative factors relating to 'Professionals must develop specialist knowledge and skills" were found to be "focusing on the importance of the work," networking, and professional development. Working with this population provides clinicians with the opportunity to contribute to humanitarian efforts, aligning with motivations to enter caring professions. ${ }^{63}$ Furthermore, self-determination theory proposes that intrinsic values such as self-development, affiliation, and community contribution are associated with greater well-being in the workplace. ${ }^{64}$ This illuminates how professionals will feel a sense of satisfaction from their work when their psychological needs are fulfilled. The development of mutual meaning and understanding has also been indicated to benefit the professional-service user relationship.

The final analytic construct, "Witnessing forced migrants' stories and trauma significantly affects professionals," addressed the intense effects of working with traumatized forced migrants and being exposed to their experiences. These effects are wide ranging and may be constructed as secondary traumatic stress, vicarious traumatization, burnout, or compassion fatigue. It is well documented that clinicians regularly working with trauma are at increased risk of experiencing secondary trauma symptoms. ${ }^{65}$ Clinicians may experience nightmares, dissociation, or anxiety and hopelessness in relation to their work and world view. Studies indicate therapists experiencing secondary traumatic stress attempt to make sense of what they hear and integrate this with existing cognitive schemas, but that this can have multiple negative implications. ${ }^{66}$

Clinicians identified several facilitators to help combat this challenge. They cited witnessing growth and resilience as a powerful and motivational experience. Several frameworks describing vicarious trauma have been developed to include concepts of vicarious resilience and vicarious posttraumatic growth. ${ }^{67}$ These seek to account for this experience, which appears to co-occur and counteract the fatigue that trauma clinicians often experienced. Concurrent with previous research, clinicians used a combination of organizational support and self-care to help manage their responses to traumas they were vicariously exposed to. ${ }^{68}$ The literature included in this review indicates being able to talk to managers and/or colleagues and engage in self-care goes some way to mitigate these effects. However, some of the evidence is mixed. ${ }^{69}$ Therefore, further research into how professionals manage these effects and what they find most helpful, or an exploration of support structures, such as group supervision, would be warranted. Organizations need to consider how these protective elements can be integrated into structures and processes, and how they can support their staff in caring for themselves. They may consider what additional supports can be put in place, or how caseloads can be managed to allow for this-for example, is a smaller caseload required when working with this population to account for the complexity and help process the emotional implications?

Finally, personal growth was found to occur by supporting forced migrants' mental health. This is again consistent with the compassion fatigue resilience model, indicating that vicarious resilience and personal growth may be closely related. Qualitative study of vicarious resilience in therapists has also identified positive personal impacts and increased hopefulness resulting from trauma work. ${ }^{70}$ Most literature that explores vicarious implications of working with trauma focuses on the experiences of therapists, and further research is needed to explore the experiences of other mental health professionals. However, the findings of this study are supported by the wider literature, which indicates working with trauma can be challenging but also rich and fulfilling. These fulfilling experiences are likely to improve staff well-being, satisfaction, and retention, and it is therefore worth exploring what specifically contributes to the experience and how professionals can "hold on" to this throughout their work.

\section{Implications}

The findings of this review may inform service providers needing to adapt their provision to improve care for disadvantaged groups, such as forced migrants. Reduction in health-care inequality is a public health concern for countries including the United Kingdom. ${ }^{71}$ This may require amendments to policy and development of clinical guidelines for best-practice care, which must recognize the complex needs and enhanced resources required for this population. Wren highlights the dangers of reactively creating services for forced migrants, detailing how this leads to insufficient and disjointed provision. ${ }^{72}$ Suitable planning and thoughtfulness is therefore required to develop effective and sustainable services.

The findings indicate that mental health professionals would benefit from appropriate training in the specialist area of forced migration. This could include training on relevant wider systems (e.g., legal, financial, and housing), cultural competency development, and working with survivors of trauma and torture. Improved understanding of the legal processes and requirements (for example, requirements to routinely present work permits at police stations), forced migrants must adhere to would help professionals to understand the processes forced migrants are going through and empathize with the associated effects. Specific gaps may include understanding the legal terminology and relevant 
implications (for example, asylum seeker, refugee, leave to remain) associated with forced migration and resettlement. Education on housing processes, reunification, financial provision, and social and legal support for forced migrants may be beneficial, as well as the gaps in these services. Access to relevant literature and information on local and national services placed to aid forced migrants should also be facilitated. Given the often complex needs of this population, interservice collaboration may be both necessary and helpful. Moreover, additional time should be allowed for clinicians to build rapport, understand service users' perspectives and needs, and conduct appointments. The findings also show access to regular structured supervision with supervisors experienced in working with this population (or who are willing to undertake specific training) should be a priority wherever possible. Where this is not possible, creative alternatives such as telephone, teleconference, or group supervision could be considered to address this need. Peer support was also highlighted as a valuable resource, and it may also be prudent to explore the possibility of peer support groups.

\section{Strengths and Limitations}

This review provides the first systematic synthesis specifically exploring the experiences of mental health professionals supporting forced migrants. This allowed a thorough exploration of the challenges and facilitators of this provision from the professionals' perspectives. All ten papers included have been published since 2007, and nine since 2013. Thus, this is a review of contemporary literature, well timed to support the further development of this field. Given the limited research in this area, the focus on qualitative research is an additional strength of this review. The constructs and themes identified help us to understand experiences and processes that can be further explored qualitatively and quantitatively to form concepts, hypotheses, and theory. ${ }^{73}$ The findings can also be used to develop study designs that are sensitive to these experiences. ${ }^{74}$ The findings have been interpreted within the context of existing theory and literature, and generally provide additional support for them, and novel findings have been produced.

All of the included studies took place in the United Kingdom, Australia, or the United States, and this may constrain the relevance to countries with comparable economic status. The characteristics of each study have been provided to allow readers to assess their applicability to other settings. As noted, methodological and contextual information was limited in some of the studies, which restricted reporting in this review. It has been argued, however, that a lack of reported information may reflect word count restrictions as opposed to methodological rigour. ${ }^{75} \mathrm{~A}$ particular area of paucity was the consideration of reflexivity and researcher bias. This was rarely discussed in the studies, and in-depth information was almost never provided. It is not possible to consider, therefore, to what extent researcher backgrounds may have influenced the interpretations of findings. To minimize this in the current review, first-person quotes were given priority over author quotes, and transparency has been promoted. This is particularly relevant, given the interpretive nature of the final stage of the analysis, highlighted by Thomas and Harden as being most controversial. ${ }^{7}$

The first author utilized a reflective journal and supervisory discussion to consider how her own background may have influenced her interpretations of findings in this review. This explored her life experiences, professional career as a trainee clinical psychologist, and interest in voluntary work abroad with vulnerable populations, although she has no experience of working with forced migrant populations. These discussions elicited themes of "wanting to get it [the analysis and interpretation] right" and sometimes of seeing forced migrants as vulnerable as opposed to resilient. The discussions allowed the primary author to become more aware of and "step away" from assumptions. All three authors have an interest in supporting forced migrant populations, and this could have had some impact on the emphasis of interpretations. To reduce potential bias introduced by these factors, the authors went back to the original papers and ensured the interpretations were grounded in them and the contexts provided.

\section{Future Directions}

The findings of this review provide vital implications for future research. This should strive to improve reporting transparency, and consideration of reflexivity in qualitative research. Research in different geographical settings will be especially useful in contributing to our understanding of mental health professionals' experiences and how they are influenced by context. Where strategies to support and improve professionals' experiences are implemented, evaluations should be undertaken to assess their effectiveness. Alternatively, evaluations may be employed to identify where care quality may be improved. These should include the perspective of both service users and providers and give voice to the perspectives of forced migrants. This review has also highlighted the issue of service access. Research investigating how we can improve access to services for forced migrants will be imperative in improving provision of mental health support for this population.

\section{Conclusion}

A novel review and thematic synthesis of mental health professionals' experiences of supporting forced migrants was conducted. The findings indicate constructs relating to 
power, specialism and trauma are broadly influential in professionals' experiences. The associated challenges and facilitating factors have been presented and explored, which can inform service practice and policy. It is hoped this will support professionals and facilitate improved quality of care for forced migrant populations. Suggestions for future research include expansion to differing geographical settings, provision of interventions to support professionals in their work, evaluation of care quality, and investigating how access to services can be improved for forced migrant populations. Global conflicts and atrocities continue to occur, suggesting that the issues pertinent to this research will not subside. It is therefore essential that we continue to examine how we can support both those affected and those working with them.

Further supplementary information regarding the characteristics and quality assessment of the studies included in the systematic review is available on request to the lead author.

\section{Declaration of Conflicting Interests}

The authors declare that there is no conflict of interest.

\section{Funding}

This research received no specific grant from any funding agency in the public, commercial, or not-for-profit sectors.

\section{Notes}

1 Brian D. Gushulak and Douglas W. MacPherson, "Population Mobility and Infectious Diseases: The Diminishing Impact of Classical Infectious Diseases and New Approaches for the 21st Century," Clinical Infectious Diseases 13 , no. 3 (2000): $776-80$.

2 Gareth Morgan, Steve Melluish, and Alice Welham, "Exploring the Relationship between Postmigratory Stressors and Mental Health for Asylum Seekers and Refused Asylum Seekers in the UK," Transcultural Psychiatry 54, no. 5-6 (2017): 653-74, https://doi.org/10.1177/1363461517737188; Shakeh Momartin, Zachary Steel, Marianio Coello, Jorge Aroche, Derrick M. Silove, and Robert Brooks, "A Comparison of the Mental Health of Refugees with Temporary versus Permanent Protection Visas," Medical Journal of Australia 185, no. 7 (2006): 357-61, https://doi .org/10.5694/J.1326-5377.2006.тво0610.X.

3 Luke Robertshaw, Surindar Dhesi, and Laura L. Jones, "Challenges and Facilitators for Health Professionals Providing Primary Healthcare for Refugees and Asylum Seekers in High-Income Countries: A Systematic Review and Thematic Synthesis of Qualitative Research," BMJ Open 7, no. 8 (2017): eo15981, https://doi.org/10.1136/ BMJOPEN-2017-015981.

4 David Palmer and Kim Ward, "Lost': Listening to the Voices and Mental Health Needs of Forced Migrants in
London," Medicine, Conflict and Survival 23, no. 3 (2007): 198-212, https://doi.org/10.1080/13623690701417345.

5 World Health Organisation (wHo), Health of MigrantsThe Way Forward: Report of a Global Consultation (Madrid: wHO, 2010).

6 Laurence J. Kirmayer, Lavanya Narasiah, Marie Munoz, Meb Rashid, Andrew G. Ryder, Jaswant Guzder, Ghayda Hassan, Cecile Rousseau, and Kevin Pottie, "Common Mental Health Problems in Immigrants and Refugees: General Approach in Primary Care," CMAJ 183, no. 12 (2011): E959-E967, https://doi.org/10.1503/cmaj.090292.

7 Natasja K. Jensen, Marie Norredam, Stefan Priebe, and Allan Krasnik, "How Do General Practitioners Experience Providing Care to Refugees with Mental Health Problems? A Qualitative Study from Denmark," BMC Family Practice 14, no. 1 (2013), https://doi.org/10.1186/1471-2296-14-17.

8 Angela Burnett and Michael Peel, "Health Needs of Asylum Seekers and Refugees," вмJ (Clinical Research Ed.) 322, no. 7285 (2001): 544-7, https://doi.org/10.1136/bmj.322.7285.544.

9 wHo, Health of Migrants.

10 Derrick Silove, Peter Ventevogel, and Susan Rees, "The Contemporary Refugee Crisis: An Overview of Mental Health Challenges," World Psychiatry 16, no. 2 (2017): 130-9, https://doi.org/10.1002/wps.20438; Mauro G. Carta, Mariola Bernal, Maria C. Hardoy, Josep M. Haro-Abad, and "The Report on the Mental Health in Eurpope" Working Group, "Migration and Mental Health in Europe (The State of the Mental Health in Europe Working Group: Appendix 1)," Clinical Practice and Epidemiology in Mental Health 1, no. 1 (2005), https://doi.org/10.1186/1745-0179-1-13.

11 Jane Noyes, "Never Mind the Qualitative Feel the Depth! The Evolving Role of Qualitative Research in Cochrane Intervention Reviews," Journal of Research in Nursing 15, no. 6 (2010): 525-34, https://doi.org/10.1177/1744987110381696.

12 Mary Dixon-Woods, Debbie Cavers, Shona Agarwal, Ellen Annandale, Antony Arthur, Janet Harvey, Ron Hsu, Savita Katbanna, Richard Olsen, Lucy Smith, Richard Riley, and Alex J. Sutton, "Conducting a Critical Interpretive Synthesis of the Literature on Access to Healthcare by Vulnerable Groups," вMC Medical Research Methodology 6, no. 1 (2006), https://doi.org/10.1186/1471-2288-6-35.

13 Robertshaw, Dhesi, and Jones, "Challenges and Facilitators for Health Professionals."

14 Aspasia Karageorge, Paul Rhodes, Rebecca Gray, and Renos Papadopoulos, "Refugee and Staff Experiences of Psychotherapeutic Services," Intervention 15, no. 1 (2017): 51-69, https://doi.org/10.1097/wTF.0000000000000137.

15 Robertshaw, Dhesi, and Jones, "Challenges and Facilitators for Health Professionals"; Karageorge et al., "Refugee and Staff Experiences of Psychotherapeutic Services."

16 Robertshaw, Dhesi, and Jones, "Challenges and Facilitators for Health Professionals"; Karageorge et al., "Refugee and Staff Experiences of Psychotherapeutic Services."

17 Alison Cooke, Debbie Smith, and Andrew Booth, "Beyond PICO: The SPIDER Tool for Qualitative Evidence Synthesis," 
Qualitative Health Research 22, no. 10 (2012): 1435-43, https://doi.org/10.1177/1049732312452938.

18 Marcia Bates, "The Design of Browsing and Berrypicking Techniques for the Online Search Interface," Online Review 13, no. 5 (1989): 407-24.

19 Yelena P. Wu, Brandon S. Aylward, Michael C. Roberts, and Spencer C. Evans, "Searching the Scientific Literature: Implications for Quantitative and Qualitative Reviews," Clinical Psychology Review 32, no. 6 (2012): 553-7, https:// doi.org/10.1016/J.CPR.2012.06.007.

20 Julie Barroso, Claudia J. Gollop, Margarete Sandelowski, Janet Meynell, Patricia F. Pearce, and Linda J. Collins, "The Challenges of Searching for and Retrieving Qualitative Studies," Western Journal of Nursing Research 25, no. 2 (2003): 153-78, https://doi.org/10.1177/0193945902250034.

21 Dixon-Woods et al., "Conducting a Critical Interpretive Synthesis."

22 Dixon-Woods et al., "Conducting a Critical Interpretive Synthesis."

23 James Thomas and Angela Harden, "Methods for the Thematic Synthesis of Qualitative Research in Systematic Reviews," BMC Medical Research Methodology 8, no. 1 (2008), https://doi.org/10.1186/1471-2288-8-45.

24 Danielle M. Campbell, Sally Redman, Louisa Jorm, Margret Cooke, Anthony B. Zwi, and Lucie Rychetnik, "Increasing the Use of Evidence in Health Policy: Practice and Views of Policy Makers and Researchers," Australia and New Zealand Health Policy 6, no. 1 (2009), https://doi .org/10.1186/1743-8462-6-21.

25 Robertshaw, Dhesi, and Jones, "Challenges and Facilitators for Health Professionals."

26 Allison Tong, Kate Flemming, Elizabeth McInnes, Sandy Oliver, and Jonathon Craig, "Enhancing Transparency in Reporting the Synthesis of Qualitative Research: ENTREQ," BMC Medical Research Methodology 12, no. 1 (2012), https:// doi.org/10.1186/1471-2288-12-181.

27 Thomas and Harden, "Methods for the Thematic Synthesis of Qualitative Research in Systematic Reviews."

28 Thomas and Harden, "Methods for the Thematic Synthesis of Qualitative Research in Systematic Reviews."

29 Thomas and Harden, "Methods for the Thematic Synthesis of Qualitative Research in Systematic Reviews."

30 Allysa J. Barrington and Jane Shakespeare-Finch, "Giving Voice to Service Providers Who Work with Survivors of Torture and Trauma," Qualitative Health Research 24, no. 12 (2014): 1686-99, https://doi.org/10.1177/1049732314549023.

31 Zoe Apostolidou, "Australian Asylum Discourses Permeating Therapeutic Work with Asylum Seekers: A Thematic Analysis of Specialist Practitioners' Experiences," Psychotherapy and Politics International 16, no. 1 (2018): e1434, https://doi.org/10.1002/ppi.1434.

32 Zoe Apostolidou, "Politicised Notions of Professional Identity and Psychosocial Practice Among Practitioners Working with Asylum Seekers and Refugees," British Journal of
Guidance and Counselling 43, no. 4 (2015): 492-503, https:// doi.org/10.108o/03069885.2014.987727.

33 Pilar Hernandez-Wolfe, Kyle Killian, David Engstrom, and David Gangsei, "Vicarious Resilience, Vicarious Trauma, and Awareness of Equity in Trauma Work," Journal of Humanistic Psychology 55, no. 2 (2015): 153-72, https://doi .org/10.1177/0022167814534322.

34 Robert Schweitzer, Sierra van Wyk, and Kate Murray, "Therapeutic Practice with Refugee Clients: A Qualitative Study of Therapist Experience," Counselling and Psychotherapy Research 15, no. 2 (2015): 109-18, https://doi .org/10.1002/capr.12018.

35 Nigar G. Khawaja and Georgia Stein, "Psychological Services for Asylum Seekers in the Community: Challenges and Solutions," Australian Psychologist 51, no. 6 (2016): 463-71, https://doi.org/10.1111/ap.12149.

36 Zoe Apostolidou, "Constructions of Emotional Impact, Risk and Meaning among Practitioners Working with Asylum Seekers and Refugees," Counselling and Psychotherapy Research 16, no. 4 (2016): 277-87, https://doi.org/10.1002/ capr.12087.

37 Allysa J. Barrington and Jane Shakespeare-Finch, "Working with Refugee Survivors of Torture and Trauma: An Opportunity for Vicarious Post-Traumatic Growth," Counselling Psychology Quarterly 26, no. 1 (2013): 89-105, https:// doi.org/10.1080/09515070.2012.727553.

38 Zoe Apostolidou, “The Notion of Professional Identity among Practitioners Working with Asylum Seekers: A Discursive Analysis of Practitioners' Experience of Clinical Supervision and Working Context in Work with Asylum Seekers," European Journal of Psychotherapy and Counselling 18, no. 1 (2016): 4-18, https://doi.org/10.108o/13642537 .2015 .1130073 .

39 Richard Laugharne and Stefan Priebe, "Trust, Choice and Power in Mental Health," Social Psychiatry and Psychiatric Epidemiology 41, no. 11 (2006): 843-52, https://doi .org/10.1007/s00127-006-0123-6.

40 Barrington and Shakespeare-Finch, "Giving Voice to Service Providers."

41 Apostolidou, "Notion of Professional Identity."

42 Barrington and Shakespeare-Finch, "Giving Voice to Service Providers."

43 Apostolidou, "Constructions of Emotional Impact, Risk and Meaning."

44 Barrington and Shakespeare-Finch, "Working with Refugee Survivors of Torture and Trauma."

45 Gillian Century, Gerrard Leavey, and Helen Payne, "The Experience of Working with Refugees: Counsellors in Primary Care," British Journal of Guidance \& Counselling 35, no. 1 (2007): 23-40, https://doi.org/10.1080/03069880601106765.

46 Barrington and Shakespeare-Finch, "Working with Refugee Survivors of Torture and Trauma."

47 Barrington and Shakespeare-Finch, "Giving Voice to Service Providers." 
48 Barrington and Shakespeare-Finch, "Working with Refugee Survivors of Torture and Trauma."

49 Barrington and Shakespeare-Finch, "Giving Voice to Service Providers."

50 Robertshaw, Dhesi, and Jones, "Challenges and Facilitators for Health Professionals."

51 Jennifer Allsopp, Nando Sigona, and Jenny Phillimore, "Poverty among Refugees and Asylum Seekers in the UK: An Evidence and Policy Review," IRiS Working Paper Series, no. 1 (2014); Neil Quinn, "Participatory Action Research with Asylum Seekers and Refugees Experiencing Stigma and Discrimination: The Experience from Scotland," Disability \& Society 29, no. 1 (2014): 58-70, https://doi.org/10.1 o8o/09687599.2013.769863.

52 Allsopp, Sigona, and Phillimore, "Poverty among Refugees and Asylum Seekers in the UK"; Quinn, "Participatory Action Research with Asylum Seekers and Refugees"; Roger Zetter and Martyn Pearl, "The Minority within the Minority: Refugee Community-Based Organisations in the UK and the Impact of Restrictionism on Asylum-Seekers," Journal of Ethnic and Migration Studies 26, no. 4 (2010): 675-97, https://doi.org/10.1080/713680501.

53 Louise Newman, Nicholas Proctor, and Michael Dudley, "Seeking Asylum in Australia: Immigration Detention, Human Rights and Mental Health Care," Australasian Psychiatry 21, no. 4 (2013): 315-20, https://doi .org/10.1177/1039856213491991.

54 Mark G. Hanson, "Counsellor Self-Efficacy: Supervision Contributions, Impact on Performance and Mediation of the Relationship between Supervision and Performance" (PhD diss., Southern Illinois University, 2006), ProQuest (3229884).

55 Laugharne and Priebe, “Trust, Choice and Power in Mental Health."

56 Suarla Fitzsimons and Ray Fuller, "Empowerment and Its Implications for Clinical Practice in Mental Health: A Review," Journal of Mental Health 11, no. 5 (2002): 481-99, https://doi.org/10.1080/09638230020023.

57 Robertshaw, Dhesi, and Jones, "Challenges and Facilitators for Health Professionals."

58 Karageorge et al., "Refugee and Staff Experiences of Psychotherapeutic Services."

59 Jeanine Suurmond, Conny Seeleman, Ines Rupp, Simone Goosen, and Karien Stronks, "Cultural Competence among Nurse Practitioners Working with Asylum Seekers," Nurse Education Today 30, no. 8 (2010): 821-26, https://doi .org/10.1016/j.nedt.2010.03.006.

60 Mina Fazel, Ruth V. Reed, Catherine Panter-Brick, and Alan Stein, "Mental Health of Displaced and Refugee Children Resettled in Low-Income and Middle-Income Countries: Risk and Protective Factors," Lancet 379, no. 9812 (2012): 250-65, https://doi.org/10.1016/So140-6736(11)60050-0.

61 Elizabeth L. Paluck and Donald P. Green, "Prejudice Reduction: What Works? A Review and Assessment of Research and Practice," Annual Review of Psychology 6o, no. 1 (2009): 339-67, https://doi.org/10.1146/annurev .psych.60.110707.163607.

62 Deborah Edwards, Peter Burnard, Doug Coyle, Anne Fothergill, and Ben Hannigan, "Stress and Burnout in Community Mental Health Nursing: A Review of the Literature," Journal of Psychiatric and Mental Health Nursing 7, no. 1 (2000): 7-14, https://doi.org/10.1046/ j.1365-2850.2000.00258.x; Kristiina Hyrkäs, "Clinical Supervision, Burnout, and Job Satisfaction among Mental Health and Psychiatric Nurses in Finland," Issues in Mental Health Nursing 26, no. 5 (2005): 531-56, https://doi .org/10.1080/01612840590931975; Tim Bradshaw, Antony Butterworth, and Hilary Mairs, "Does Structured Clinical Supervision during Psychosocial Intervention Education Enhance Outcome for Mental Health Nurses and the Service Users They Work With?," Journal of Psychiatric and Mental Health Nursing 14, no. 1 (2007): 4-12, https://doi .org/10.1111/j.1365-2850.2007.01021.x.

63 Jennifer M. Newton, Cherene M. Kelly, Anne K. Kremser, Brian Jolly, and Stephen Billett, "The Motivations to Nurse: An Exploration of Factors amongst Undergraduate Students, Registered Nurses and Nurse Managers," Journal of Nursing Management 17, no. 3 (2009): 392-400, https://doi .org/10.1111/j.1365-2834.2008.00945.x.

64 Richard M. Ryan and Edward L. Deci, "Self-Determination Theory and the Facilitation of Intrinsic Motivation, Social Development, and Well-being," American Psychologist 55, no. 1 (2000): 68-78.

65 Hernandez-Wolfe et al., "Vicarious Resilience, Vicarious Trauma, and Awareness of Equity in Trauma Work."

66 Century, Leavey, and Payne, "The Experience of Working with Refugees."

67 Marne Ludick and Charles R. Figley, "Toward a Mechanism for Secondary Trauma Induction and Reduction: Reimagining a Theory of Secondary Traumatic Stress," Traumatology 23, no. 1 (2017): 112-23, https://doi.org/10.1037/ trmooooog6.

68 Ludick and Figley, "Toward a Mechanism for Secondary Trauma Induction and Reduction"; Kyle D. Killian, "Helping till It Hurts? A Multimethod Study of Compassion Fatigue, Burnout, and Self-Care in Clinicians Working with Trauma Survivors," Traumatology 14, no. 2 (2008): 32-44, https://doi.org/10.1177/1534765608319083.

69 Lisa S. Elwood, Juliette Mott, Jeffrey M. Lohr, and Tara E. Galovski, "Secondary Trauma Symptoms in Clinicians: A Critical Review of the Construct, Specificity, and Implications for Trauma-Focused Treatment," Clinical Psychology Review 31, no. 1 (2011): 25-36, https://doi.org/10.1016/J .CPR.2010.09.004.

70 Hernandez-Wolfe et al., "Vicarious Resilience, Vicarious Trauma, and Awareness of Equity in Trauma Work."

71 Robertshaw, Dhesi, and Jones, "Challenges and Facilitators for Health Professionals."

72 Karen Wren, "Supporting Asylum Seekers and Refugees in Glasgow: The Role of Multi-Agency Networks," Journal 
of Refugee Studies 20, no. 30 (2007): 391-413, https://doi .org/10.1093/jrs/femoo6.

73 Pamela O. Atieno, "An Analysis of the Strengths and Limitation of Qualitative and Quantitative Research Paradigms," Problems of Education in the 21st Century 13, no. 1 (2009): 13-18.

74 Karin Hammarberg, Maggie Kirkman, and Sheryl de Lacey, "Qualitative Research Methods: When to Use Them and How to Judge Them," Human Reproduction 31, no. 3 (2016): 498-501, https://doi.org/10.1093/humrep/dev334.

75 Salla Atkins, Simon Lewin, Helen Smith, Mark Engel, Atle Fretheim, and Jimmy Volmink, "Conducting a MetaEthnography of Qualitative Literature: Lessons Learnt," BMC Medical Research Methodology 8, no. 1 (2008), https:// doi.org/10.1186/1471-2288-8-21; Angela Harden, Jo Garcia, Sandy Oliver, Rebecca Rees, Jonathon Shepherd, Ginny Brunton, and Ann Oakley, "Applying Systematic Review Methods to Studies of People's Views: An Example from
Public Health Research," Journal of Epidemiological Community Health 58 (2004): 794-80o, https://doi.org/10.1136/ jech.2003.014829.

76 Thomas and Harden, "Methods for the Thematic Synthesis of Qualitative Research in Systematic Reviews."

Iona Tynewydd is a clinical psychologist at Betsi Cadwaladr University Health Board. She can be reached at Iona. Tynewydd@wales.nhs.uk.

Sophie North is a lecturer at the University of East Anglia. She can be reached at S.North1@uea.ac.uk

Imogen Rushworth is a clinical senior lecturer in clinical psychology at the University of East Anglia, Norwich. She can be reached atI.Rushworth@uea.ac.uk. 